\title{
USO DO SOFTWARE SPHINX DURANTE A REALIZAÇÃO DE ANÁLISE TEXTUAL DISCURSIVA: OUTROS PERCURSOS
}

\section{USE OF THE SPHINX SOFTWARE DURING THE REALIZATION OF DISCURSIVE TEXTUAL ANALYSIS: OTHER TRAJECTORIES}

\author{
Marlúbia Corrêa de Paula, Lori Viali, Gleny Terezinha Duro Guimaraes \\ Pontifícia Universidade Católica do Rio Grande do Sul \\ E-mail:marlubia.paula@acad.pucrs.br, viali@pucrs.br, gleny@pucrs.br
}

\section{Resumo}

Este texto trata de apresentar uma pesquisa realizada para compor uma dissertação que utilizou a ATD (Análise Textual Discursiva) e a Prática Discursiva de Spink aliada ao uso do software Sphinx. Para verificar os softwares utilizados em pesquisas qualitativas no Brasil, foi realizada uma busca no Portal Capes (Coordenação de Aperfeiçoamento de Pessoal de Nível Superior), onde foram encontrados 69 trabalhos (2010-2014), dos quais 33 utilizaram softwares durante o processo de análise de dados. O objetivo deste texto é apresentar o modo como ocorreu o uso do software Sphinx para auxiliar o processo de ATD. A questão de pesquisa envolveu evidenciar que o uso do software não corrompe a ATD e ainda, amplia as possibilidades de imersão agilizando a digitação inicial das respostas dos questionários. Conclui-se que o uso de software no Brasil em pesquisa qualitativa, nos últimos cinco anos, ainda é modesto.

Palavras-chave: software para análise qualitativa. pesquisa qualitativa. metodologia qualitativa.

\section{Abstract}

This text attend to submit a research performed to compose a thesis that used the (ATD) Discursive Textual Analysis and the Discursive Practice of Spink allied to the use of the software Sphinx. To check the software used in qualitative research in Brazil, was performed a search in the Capes Portal (Coordination of Improvement of Personnel in Higher Level), where found 69 jobs (2010-2014), of which 33 have used software during the process of analysis of data. The objective of this text is to present the way as occurred the use of the software Sphinx to assist the process of ATD. The question of the research involved evidence that the use of the software not defile the ATD and still, expands the possibilities of immersion, since expedite the typing of initial of the questionnaire responses. It is concluded that the use of software in Brazil, in the last five years, is still modest.

Palavras-chave: software for qualitative analysis. qualitative research. qualitative methodology. 


\section{INTRODUÇÃO}

Este texto apresenta alguns dos momentos que fizeram parte do estudo realizado para compor uma dissertação de mestrado de título: Um novo olhar sobre a Transposição Didática: O início de uma proposta para o uso das TIC na Educação Básica do PPGEDUCEM (Programa de Pós-Graduação em educação em Ciências e Matemática), realizada no período de 2013-2014, na PUCRS (Pontifícia Universidade Católica do Rio Grande do Sul), conforme Paula (2014).

Quanto aos aspectos metodológicos, considera-se que metodologia é o caminho do pensamento ou da prática exercida na abordagem da realidade, e deste modo inclui simultaneamente a teoria da abordagem (o método), os instrumentos de operacionalização do conhecimento (as técnicas) e tudo isto envolve a criatividade do pesquisador (sua experiência, sua capacidade pessoal e sua sensibilidade), conforme Minayo (2011).

Trata-se de um estudo de caráter qualitativo utilizando-se de instrumentos que foram constituídos por questionários estruturados (I e II) e entrevistas semiestruturadas gravadas e posteriormente transcritas (com uma amostra de 6 sujeitos pertencentes ao grupo de 23 professores). Os participantes da pesquisa, que responderam aos dois questionários, eram professores de uma escola do interior do Rio Grande do Sul que possuía lousa eletrônica (em uso) em todas as suas 10 salas de aula.

O questionário I buscava identificar os sujeitos de pesquisa para compor o perfil do grupo estudado. O questionário II pretendia detectar as ideias destes sujeitos sobre a forma como utilizavam as TIC (Tecnologias de Informação e Comunicação) em suas salas de aula. O número de alunos atendidos pela escola era de duzentos e sessenta. A população do município era naquela ocasião de mil duzentos e quarenta e quatro habitantes. Esta era a única escola de ensino fundamental, naquela região.

O foco da dissertação realizada foi analisar se os professores utilizavam as TIC como um 
elemento acessório ou integrante em suas aulas, conforme Borba \& Penteado (2005). Como elemento acessório as TIC, apenas revelam uma nova forma "para expor" os conteúdos.

Como integrantes das aulas, podem colaborar possibilitando outra forma de realização da aula. Outras atividades elaboradas para o uso de TIC podem remover o professor da posição de exposição de conteúdos prontos para o papel de mediador do processo de ensino/aprendizagem. Todas estas colocações surgem do fato de que apenas a inserção de mídias não determina modificações de práticas pedagógicas. No entanto, ao fazer uso das TIC, em decorrência do desenvolvimento de outras atividades, no meio on-line, as práticas podem ser alteradas. E, foi para observar estas práticas pedagógicas, em salas com uso de lousas eletrônicas, apoiando-se também em questionários e entrevistas gravadas, que foi realizada a pesquisa que uniu ATD e uso de software Sphinx.

O método de análise para uso nas questões escolhidas para reflexões do segundo questionário foi a ATD (Análise Textual Discursiva), de Moraes e Galiazzi (2011). Para as entrevistas gravadas e transcritas, utilizou-se como forma de análise e apresentação a Prática Discursiva, conforme Spink (2000).

A escolha do software Sphinx e a ideia de utilizá-lo durante a realização da ATD, surgiu no decorrer da coleta de dados da pesquisa, na fase de aplicação dos questionários. Neste momento, a pesquisadora realizava uma disciplina de Análise de Conteúdo e de Discurso (disciplina oferecida pelo Programa de Pós-Graduação em Serviço Social da PUCRS) quando percebeu o quanto, o uso de um software que permitisse a digitação dos questionários e das respostas obtidas poderia contribuir para a agilidade do processo de análise. E, ao mesmo tempo, liberaria um maior espaço para as leituras e releituras dos questionários, em função das necessárias imersões, para captar as emergências, ao longo das unitarizações. Esta foi a operacionalização do conhecimento descrita por Minayo (2011), escolhida pela pesquisadora. 
O uso de software Sphinx, mantém as imersões que são requeridas pela ATD, pois o pesquisador só conseguirá digitar suas unidades de significado/sentido após ter realizado várias leituras das respostas dos questionários. Só após as idas e vindas, poderá desconstruir as respostas, para então digitá-las na plataforma do Sphinx. Outra questão que justifica o uso deste software é que as respostas dos sujeitos pesquisados retornaram registradas manualmente. Se tivesse ocorrido o retorno via e-mail, ter-se-iam outros softwares, que poderiam ter sido utilizados, como por exemplo o Qualtrics.

Quanto aos objetivos deste texto, trata-se de divulgar uma pesquisa qualitativa que envolveu o uso de ATD e da Prática Discursiva de Spink, como modo de obtenção e apresentação dos resultados obtidos, utilizando-se de um software, com viés qualitativo, nas etapas de digitação das unidades de significado/sentido, também auxiliando na obtenção das categorias intermediárias, uma vez que há possibilidade de realizar correlações entre as unidades verificando o que pode emergir das construções e desconstruções das respostas destes sujeitos de pesquisa.

A digitação, no processo de ATD normalmente ocorre via editor de textos, ou planilhas eletrônicas. No entanto, estas ferramentas são limitadas, pois não apresentam em sua estrutura possibilidades imediatas de análise qualitativa, dos dados. Com o uso do software, as percepções decorrentes das leituras são confirmadas, por meio das diversas possibilidades que esta plataforma oferece.

A junção de ATD e da Prática Discursiva de Spink refere-se dentro da metodologia, como sendo um dos aspectos da criatividade do pesquisador, conforme Minayo (2011). Esta opção torna-se um processo desafiador e ousado, na medida em que procura inovar com outras técnicas além da tradicional análise de conteúdo de Bardin, presente na maioria das teses e dissertações selecionadas, que serão descritas, para complementar este texto.

Quanto ao problema gerador deste texto, pode-se afirmar que envolveu evidenciar a forma 
como o uso do software Sphinx, facilitou o desenvolvimento da dissertação ampliando a visualização das Unidades de Sentido e potencializando a obtenção das Categorias. Este facilitar descrito, não eliminou o esforço da pesquisadora, nas desconstruções necessárias da ATD. No entanto, com o software a visualização, por meio de janelas disponíveis das possibilidades que iam surgindo, cada vez que uma nova resposta era digitada impulsionava as ideias da pesquisadora, no sentido de encorajamento, para apresentar as respostas daqueles sujeitos de pesquisa, sobre o modo, como faziam uso de TIC, naquelas salas de aula, daquela escola.

Para enfatizar o uso de softwares junto a pesquisa quali e verificar como isto tem ocorrido, utilizou-se dos resultados de uma busca junto ao Banco de Teses e Dissertações da CAPES (Coordenação de Aperfeiçoamento de Pessoal de Ensino Superior), à fim de verificar como tem ocorrido este uso, nos últimos 5 anos.

Percebe-se que após a realização da dissertação e a busca no Portal Capes, que embora o uso de software na pesquisa quali ainda seja modesto, tem apresentado um crescimento considerável nos últimos anos. No entanto, o uso de computadores em análises qualitativas ainda enfrenta resistências. Mas, como tais associações, que envolvem pesquisa quali e software são encontradas na literatura somente após a década de 80, conforme Moreira (2007), considera-se que, este procedimento, ainda é recente. Como resultante, da busca no Portal CAPES, convém relatar que foi encontrada esta junção, no texto de dezoito dissertações e de apenas, uma tese.

Outro fato, que pode estar limitando o uso de software, em processos de análises textuais, pode estar relacionado ao conhecimento que precisa ter o pesquisador para utilizar softwares que inserem codificações em seus processos, conforme Lages e Godoy (2008). Desta forma a falta de conhecimento por parte do pesquisador iniciante, poderá levar a relações incorretas e este receio, torna o editor de texto uma ferramenta, de maior (talvez não o melhor) acesso. 
Antes de dominar o software faz-se necessário, dominar os procedimentos da análise textual escolhida. O uso do software, se não for considerado o elemento central, será adequado. Quanto a isto, o uso de Sphinx torna-se adequado em fase inicial de experiência do pesquisador, pois neste processo não há necessidade de codificações. Seu uso é simples e de fácil acesso.

O Sphinx apresenta uma interface em português, com comunicação direta com o Microsoft Office. Este software realiza análise de dados quantitativos (uni, bi e multivariada) e qualitativos (categorização de discursos, entrevistas, sugestões, opiniões, etc.), conforme Freitas e Muniz (2009).

Dando sequência a este texto apresenta-se então o modo como foi desenvolvida a ATD com o uso do software (minimizando ansiedades no percurso) e após, faz-se a apresentação dos softwares utilizados em teses e dissertações nos últimos 5 anos, disponíveis no Portal CAPES.

\section{SPHINX NA ANÁLISE TEXTUAL DISCURSIVA (ATD): PROCEDIMENTOS INICIAIS}

O trabalho do pesquisador para coletar seus dados revigora-se quando encontra uma forma renovada de analisá-los e apresentá-los a comunidade, na qual está inserido. Quanto a ATD, os autores não só em sua obra Análise Textual Discursiva, mas em diversos artigos deixam claro, o quanto a ATD é um processo que produz transformações também no pesquisador, ao longo de etapas (unitarização, categorização, comunicação) até chegar a um processo autoorganizado, o que possibilita uma nova compreensão do objeto da pesquisa, conforme Moraes e Galiazzi (2011).

Porém de início, os jovens pesquisadores ainda em processo de construção de suas metodologias, mergulham não só em textos a serem estudados, mas também em momentos de incertezas quanto à técnica de análise de seus dados. Deste modo: "A fase da análise de 
dados e informações constitui-se em momento de grande importância para o pesquisador especialmente numa pesquisa de natureza qualitativa. Constitui razão de ansiedade e insegurança para grande número de alunos de mestrado (MORAES; GALIAZZI, 2006, p. 118). Deste modo, pode-se afirmar que o uso de softwares em análises textuais é um caminho a ser explorado. Deve-se sim buscar este conhecimento e divulgar outras formas de otimizar as etapas de pesquisas em nível strictu senso. Para Lévy:

\begin{abstract}
Novas maneiras de pensar e de conviver estão sendo elaboradas no mundo das telecomunicações e da informática. As relações entre os homens, o trabalho e a própria inteligência dependem, na verdade, da metamorfose incessante de dispositivos informacionais de todos os tipos. Escrita, leitura, visão, audição, criação, aprendizagem são capturados por uma informática cada vez mais avançada. Não se pode mais conceber a pesquisa científica sem uma aparelhagem complexa que redistribui as antigas divisões entre experiência e teoria (LÉVY, 1995, p. 4).
\end{abstract}

Ao unir software e ATD, quando se dá início ao processo de análise devem ser digitadas todas as perguntas. De igual modo, para cada pergunta digitam-se todas as respostas obtidas, que serão desconstruídas, dando origem as unidades de significado/sentido.

O uso de um software ou de um simples editor de textos, não altera as digitações iniciais, quanto à quantidade. Mas, quanto a qualidade o software Sphinx, pelo seu formato, agiliza a digitação, pois permite confrontar as desconstruções e realizar correlações a todo momento. Nesta pesquisa, para cada pergunta foram digitadas as vinte e três respostas, já no formato de unidades de significado/sentido. No momento da digitação, percebeu-se que ocorreram momentos nos quais, os sujeitos pesquisados responderam exatamente com o mesmo teor. Desta forma, 23 respostas dos questionários, podem sofrer aumentos/diminuições em termos de quantidade de respostas, pois as desconstruções ampliam/reduzem as respostas de início, quantitativamente. 
Nota-se que ao ler e ir marcando (sublinhando, colorindo) as respostas, nos questionários, percebe-se desde o início a predominância de determinado sentido das ideias que estão sendo comunicadas. A pergunta (do questionário) e as respostas (dos sujeitos pesquisados) devem ser lidas várias vezes, para evitar que o pesquisador faça pressuposições desejáveis a sua pesquisa, mas que não foram "ditas" pelos entrevistados.

O software confirma as percepções do pesquisador. Ele, não faz pressuposições nem julgamentos sobre as respostas obtidas, no entanto ele confirma ou não, por meio de correlações que oferece, se tais percepções estão de fato, sendo sustentadas pelas respostas dos sujeitos pesquisados. E para que ocorram tais correlações, basta requerê-las, numa das janelas disponíveis na interface do software.

As imersões são inevitáveis em análises textuais discursivas. O uso do software para a digitação, não inibe esta ocorrência. Desta forma, não ocorrem afastamentos dos textos oferecidos nas respostas, pois a cada leitura, o pesquisador aproxima-se mais do sujeito pesquisado, como afirmam Moraes e Galiazzi (2011).

A cada leitura, as respostas são particionadas, a ponto de irem construindo novas sequências de ideias. Tudo isto muda constantemente a cada vez que nova leitura das respostas dos sujeitos pesquisados é realizada. Pois, é por meio dessas interpretações que tem início as unitarizações. São sucessivas idas e vindas às respostas, que vão constituindo ideias para a formação do resultado "inicial, intermediário e final", que dá origem respectivamente, as categorias.

No entanto, deve-se destacar que não há exatamente, uma categoria final, pois sempre haverá uma nova constatação a ser realizada a cada leitura, logo a ATD, de Moraes e Galiazzi (2011) constitui-se, como um processo inacabado em constante construção, onde não h.

Ao utilizar-se o software Sphinx, as sucessivas idas e vindas, não deixam de ocorrer. O que se 
percebe é que o modo de registrar as respostas dos questionários é que torna este software um auxiliar de imersões.

Ao invés de marcar em tabelas de editores de texto as ideias que estão contidas nas respostas dos entrevistados, digitam-se estas ideias, uma após a outra. Isso possibilita maior rapidez na realização da análise.

Abaixo visualiza-se a digitação destas ideias que foram obtidas das respostas dos vinte e três sujeitos pesquisados. Observa-se que para cada pergunta haverá cerca de vinte e três respostas. Algumas vezes mais de vinte e três e em outras vezes, um número menor de respostas. Esta variação ocorre, pois muitas vezes as pessoas respondem de modo longo a cada questão e em outras vezes simplesmente, não respondem. A Figura1 ilustra algumas das questões respondidas no questionário II, por uma das professoras entrevistadas.

Figura 1. Questionário de número 13 - Recorte das respostas dos professores.

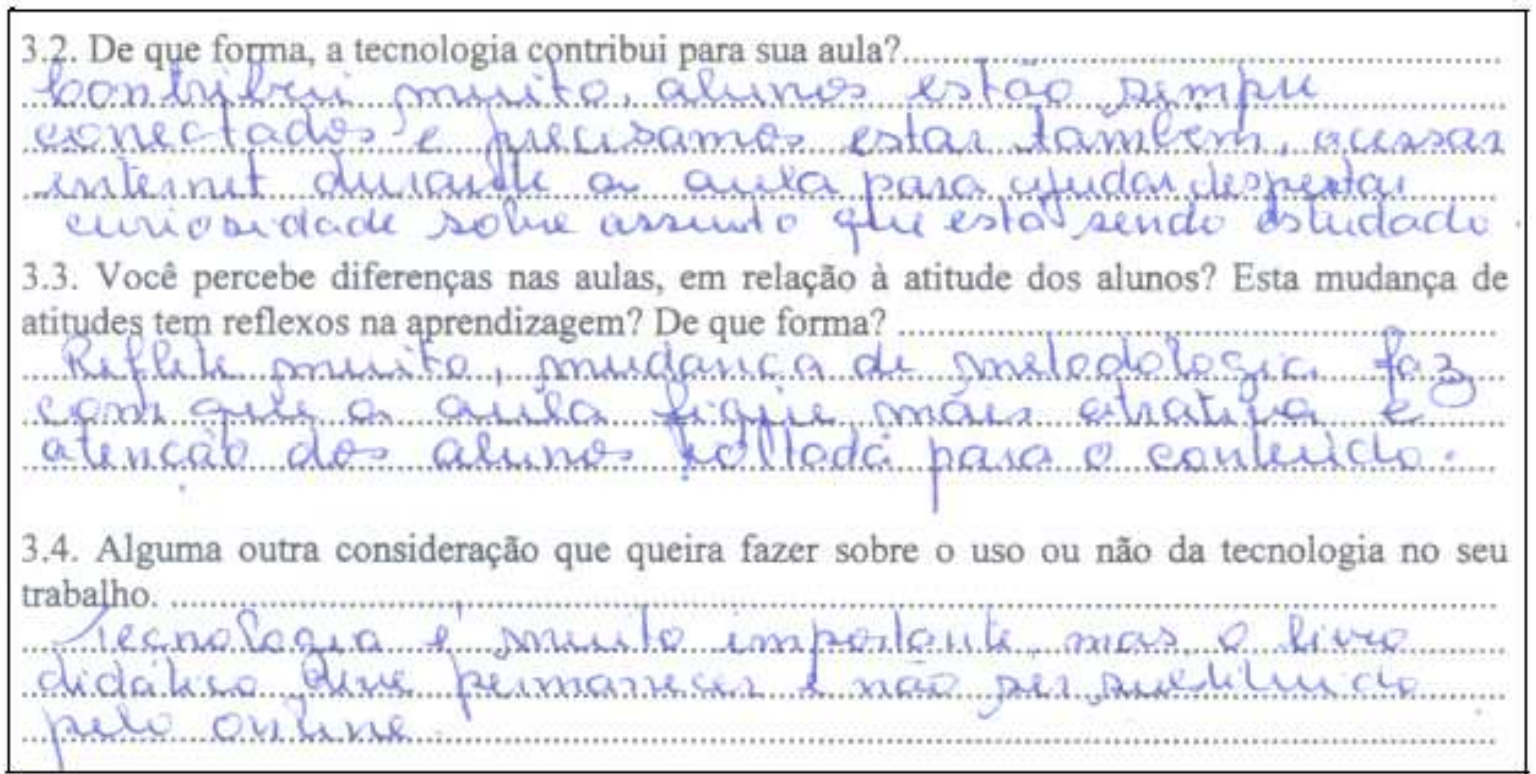

Fonte: Paula (2014, p. 46).

O software Sphinx, possibilita verificar no final da digitação se ocorreu uma repetição de termos utilizados nas respostas e então permite emitir um relatório para cada questão. Os 
vinte e três questionários, foram lidos e uma a uma as questões foram digitadas no Sphinx. Para cada questão foram digitadas pelo pesquisador as respostas obtidas, conforme o que se observa na Figura 2.

Figura 2. Recorte de digitação de questões no Sphinx.

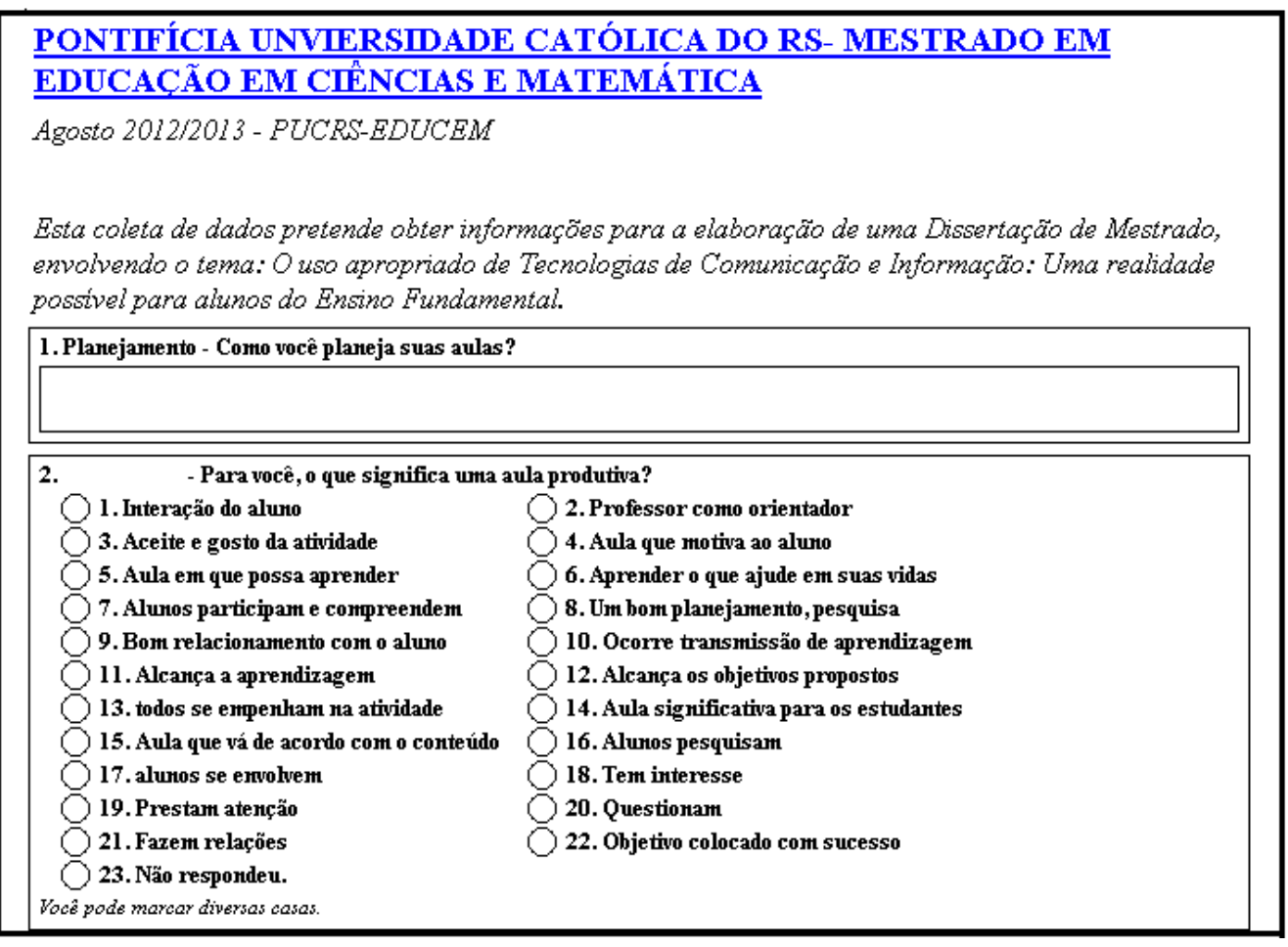

Fonte: Paula (2014, p.74).

Esta é a visualização apresentada via Sphinx, para cada questão digitada. No Sphinx, após ler cada questão, respondida pelos sujeitos pesquisados o pesquisador tem em mãos todas as possíveis unidades de sentido resultantes destas respostas.

Atualmente estão sendo utilizados softwares de aplicação on-line, como o Qualtrix. Esta ferramenta possibilita que as respostas sejam inseridas pelo próprio respondente e os relatórios gerados ao pesquisador são obtidos ao longo do processo acompanhando, desta forma, a evolução dos questionários preenchidos. Porém, quando os questionários são preenchidos pelos sujeitos e não são digitados, por estes, o Sphinx oferece melhores possibilidades para a realização da ATD. 
Com o uso, desse software para digitar as respostas de cada pergunta, o pesquisador, precisa realizar a desconstrução de tais respostas o que faz com que a análise textual discursiva, não sofra qualquer alteração em suas etapas. Esse uso, apenas agiliza as digitações, em termos de melhor uso do tempo, para novas leituras e imersões. Para pesquisas com grande número de sujeitos pesquisados outros softwares como Atlas Ti e Nvivo são indicados.

Abaixo, apresenta-se outra forma de visualização das respostas dos vinte e três sujeitos, pesquisados.

Quadro 1. Observando as categorias e suas emergências.

\begin{tabular}{|l|r|r|}
\hline \multicolumn{1}{|c|}{ Facilidades da lousa } & Freq. & $\%$ \\
\hline O uso do vídeo ou melhor do DVD & 1 & 4,3 \\
\hline Nenhuma & 1 & 4,3 \\
\hline ainda nẫo considero possivel fazer uma análise concreta & 1 & 4,3 \\
\hline Antes usava materiais didáticos(livros,revistas jornais) & 1 & 4,3 \\
\hline O uso do quadro negro e livro, mas sem seguir o livro a risca & 1 & 4,3 \\
\hline Imagens visualizadas & 1 & 4,3 \\
\hline Jogos filmes, colorido das palavras & 2 & 8,7 \\
\hline Técnicas de concetraçẫo & 1 & 4,3 \\
\hline Técnicas de motivaçẫo & 1 & 4,3 \\
\hline Quadro negro e giz & 1 & 4,3 \\
\hline Enriquece as aulas & 1 & 4,3 \\
\hline nẫo respondeu & 12 & 52,2 \\
\hline Aprendizagem dos alunos & 1 & 4,3 \\
\hline ToTaL oBs. & 23 & \\
\hline
\end{tabular}

A quantidade de citaçốes é superior à quantidade de observaçốes devido às respostas múltiplas (13 no máximo).

Fonte: Paula (2014, p.79) .

Quando não se obtém uma resposta (como pode-se observar no Quadro I), isto também contribui para a análise textual, pois evidencia que de fato, o assunto tratado constitui-se num espaço de dúvidas, para os sujeitos pesquisados. É possível verificar observando esta questão que $52,2 \%$ dos professores não sabem explicar quais as facilidades do uso da lousa 
em sala de aula. Isto numa investigação que busca saber sobre o uso de TIC em sala de aula constitui-se num dado de real importância. Mas, nada surge ao acaso.

A própria imersão do pesquisador, irá apontar os rumos das respostas, as quais o próprio pesquisador poderá confirmar via software. Os resultados não são determinados pelo software, mas podem ser um ponto de apoio, para as compreensões do pesquisador, após suas imersões.

É das imersões do pesquisador que surgem as aproximações e distanciamentos das ideias apresentadas pelos sujeitos pesquisados, em relação à pesquisa que está sendo realizada.

$\mathrm{Na}$ tabela abaixo apresenta-se a transcrição das respostas dos questionários digitadas em Sphinx, para o formato que compõe o processo da ATD, demonstrando desta forma que da análise resultarão num dado momento, as categorizações.

Quadro 2. Obtendo a Unitarização e Categorização com editor de textos.

\begin{tabular}{|c|c|c|}
\hline \multicolumn{3}{|c|}{ Para você o que significa aula produtiva? } \\
\hline $\begin{array}{l}\text { Categorias } \\
\text { intermediárias }\end{array}$ & Categorias iniciais & UNIDADES DE SENTIDO \\
\hline Atitude do aluno & $\begin{array}{l}\text { Reflete nas atitudes do aluno } \\
\text { (pesquisa, interesse, envolvimento, } \\
\text { prestam atenção, questionam e } \\
\text { fazem relações) (1) }\end{array}$ & $\begin{array}{l}\text { Interação do aluno (1) } \\
\text { Alunos pesquisam (1) } \\
\text { Alunos se envolvem (1) } \\
\text { Alunos têm interesse (1) }\end{array}$ \\
\hline Atitude do professor & $\begin{array}{l}\text { Professor orientador (2) } \\
\text { Motivadora do aluno (3) }\end{array}$ & $\begin{array}{l}\text { Gostam da atividade (1) } \\
\text { Professor como orientador do aluno (2) } \\
\text { Aula que motiva ao aluno (3) } \\
\text { Aula em que possa aprender (3) } \\
\text { Alunos participam e compreendem (3) }\end{array}$ \\
\hline
\end{tabular}

Fonte: Adaptado de Quadro 4 - Paula (2014, p. 75-76).

Diante do que foi exposto, percebe-se que os momentos da ATD, não são alterados pelo uso do software Sphinx. No entanto, ao buscar por trabalhos em nível stricto sensu, no Portal Capes, percebe-se que o uso de softwares para análises textuais em pesquisas qualitativas, ainda ocorre em números modestos, conforme será apresentado no próximo tópico. Ainda prevalece a ideia do uso de softwares para dados quantitativos, ou então, no interior das pesquisas como uma ferramenta, para o ensino/aprendizagem de um determinado conteúdo, não raras às vezes, ligado a disciplina de matemática. 


\section{SOFTWARES EM PESQUISA QUALITATIVA NO BRASIL: LEVANTAMENTO REALIZADO NO PORTAL CAPES}

Para verificar o uso de softwares em pesquisa qualitativa no Brasil, analisaram-se por meio do Portal CAPES, 69 trabalhos (entre teses e dissertações), dos quais apenas 33 trabalhos utilizaram-se de softwares durante a elaboração das análises textuais.

Os demais trabalhos, mencionados anteriormente, utilizaram softwares como o Geogebra e o Winplot, entre outros, com o intuito de desenvolver conteúdos específicos durante aulas. Os trabalhos foram localizados no período de 2010-2014.

No quadrola abaixo, apresentam-se os trabalhos analisados, que envolveram o uso de Sphinx, Nvivo e Atlas Ti, encontrados em maior número de trabalhos, seguidos de outros, tais como Icode, Qualtrics, Chic, Guindace, Pajek, Pq Method, Alceste, Graph-prism, Mineraforum e Smartpls (PAULA; GUIMARAES; VIALI, 2015).

Quadro 3. Softwares utilizados para auxílio da pesquisa qualitativa - DISSERTAÇÕES e TESES.

\begin{tabular}{|l|c|l|c|c|}
\hline \multicolumn{1}{|c|}{ Instituição } & Ano & \multicolumn{1}{|c|}{ Cursos } & Método análise & Software \\
\hline 1. UFSCar & 2011 & $\begin{array}{l}\text { Mestrado acadêmico em ciência da computação } \\
\text { engenharia de software }\end{array}$ & Técnica coding & Icode \\
\hline 2. UFRJ & 2011 & Mestrado acadêmico em enfermagem & - & Atlas. Ti \\
\hline 3. UFSP & 2011 & Mestrado acadêmico em psicobiologia & - & Nvivo \\
\hline 4. PUCDF & 2012 & $\begin{array}{l}\text { Mestrado profissional em gestão do conhecimento } \\
\text { e da tecnologia da informação }\end{array}$ & Nvivo \\
\hline 5. PUCPR & 2011 & Mestrado acadêmico em administração & - & Qualtrics \\
\hline 6. UFCeará & 2012 & $\begin{array}{l}\text { Mestrado profissional em ensino de ciências e } \\
\text { matemática }\end{array}$ & $\begin{array}{c}\text { Árvores de } \\
\text { similaridade }\end{array}$ & Chic \\
\hline 7. UFPB & 2011 & Mestrado acadêmico em enfermagem & AD/Bardin & Atlas Ti \\
\hline 8. Uniban & 2012 & Mestrado acadêmico em educação matemática & $\begin{array}{c}\text { Projeto de } \\
\text { experimentos } \\
\text { de Cobb }\end{array}$ & - \\
\hline 9. Ufpe & 2012 & $\begin{array}{l}\text { Mestrado acadêmico em educação matemática e } \\
\text { tecnológica }\end{array}$ & Atlas Ti \\
\hline 10. Pucminas & 2011 & Mestrado profissional em administração & AC & Atlas Ti \\
\hline
\end{tabular}




\begin{tabular}{|c|c|c|c|c|}
\hline 11. Unesp & 2012 & Mestrado acadêmico em educação & $A C$ & Nvivo \\
\hline 12. UFSP & 2011 & Mestrado acadêmico em psicobiologia & $A C$ & $\mathrm{~N}$ vivo 8 \\
\hline 13. Ufpe & 2012 & Mestrado acadêmico em ciências da computação & - & Guindace \\
\hline 14. UFSC & 2012 & Mestrado acadêmico em odontologia & AC/Bardin & $\mathrm{N}$ vivo 9 \\
\hline 15. Pucsp & 2011 & Mestrado profissional em educação matemática & $\begin{array}{l}\text { Árvore de } \\
\text { similaridade }\end{array}$ & Chic \\
\hline 16. Pucpr & 2012 & Mestrado acadêmico em educação & AC/Bardin & Sphinx léxica \\
\hline 17. Ufms & 2011 & $\begin{array}{l}\text { Mestrado acadêmico em doenças infecciosas e } \\
\text { parasitárias }\end{array}$ & $\begin{array}{l}\text { Método do } \\
\text { discurso do } \\
\text { sujeito coletivo }\end{array}$ & $\begin{array}{l}\text { Quali/quanti } \\
\text { soft }\end{array}$ \\
\hline 18. UFPB & 2011 & Mestrado acadêmico em enfermagem & AC/Bardin & Atlas \\
\hline 19. UFPB & 2012 & Mestrado acadêmico em administração & $\begin{array}{l}\text { ARS (Análise de } \\
\text { redes sociais) }\end{array}$ & Pajek \\
\hline 20. Ufube & 2012 & Mestrado acadêmico em estudos linguísticos & Análise fatorial & Pq method \\
\hline 21. UnB & 2012 & Mestrado acadêmico em agronegócios & Análise lexical & Alceste \\
\hline 22.Pucpr & 2012 & Mestrado acadêmico em administração & AC & Atlas Ti \\
\hline 23. Ufviçosa & 2012 & Mestrado acadêmico em economia doméstica & $A C$ & Nvivo \\
\hline 24. IEBUnicastel & 2012 & Mestrado acadêmico em engenharia biomédica & $\begin{array}{l}\text { Abordagem } \\
\text { quali/quanti }\end{array}$ & Graph prism \\
\hline 25. Ufgo & 2012 & Mestrado acadêmico em enfermagem & Bardin & Atlas $\mathrm{Ti}$ \\
\hline 26. UFPR & 2012 & Mestrado acadêmico em administração & $\begin{array}{c}\text { Análise } \\
\text { multivariada }\end{array}$ & Qualtrics/SPSS \\
\hline 27. Pucpr & 2012 & Mestrado acadêmico em administração & $A C$ & Atlas Ti \\
\hline 28. UnB & 2011 & Doutorado em psicologia clínica e cultura & Análise lexical & Alceste \\
\hline 29. UFRGS & 2011 & Doutorado em informática na educação & $\begin{array}{l}\text { Análise de } \\
\text { Fórum de } \\
\text { discussão }\end{array}$ & Minera Fórum \\
\hline $\begin{array}{l}\text { 30. UF São } \\
\text { Carlos }\end{array}$ & 2012 & Doutorado em engenharia de produção & $A C$ & Nvivo \\
\hline 31. USP & 2012 & Doutorado em engenharia de produção & - & Smartpls \\
\hline 32. PUCSP & 2012 & Doutorado em educação (currículo) & - & $\mathrm{CHIC}$ \\
\hline 33. UFSC & 2011 & Doutorado em enfermagem & $\begin{array}{l}\text { Categoria de } \\
\text { análise }\end{array}$ & Atlas Ti \\
\hline
\end{tabular}

Fonte: Paula, Guimarães, Viali (2015, p.60-61)

Como pode ser observado, na tabela acima, outros softwares foram encontrados para realização de análises textuais, mas Atlas Ti e Nvivo foram às escolhas predominantes nos 33 trabalhos analisados. As dissertações (em número de 27) superaram o número de teses (em número de 6), com uso de softwares em análises textuais qualitativas. 
A escolha do Sphinx para uso em dissertações ainda não é comum no Brasil, pois apenas um dos 69 trabalhos encontrados no Portal CAPES, utilizou este software. No entanto, como o Banco de Teses, não apresenta ainda os trabalhos defendidos no ano de 2014, este dado pode ser alterado, numa próxima atualização desse portal. Os cursos de enfermagem, seguidos dos cursos de administração, ambos de mestrado aparecem com maior frequência, quanto ao uso de análises textuais com apoio em softwares para uso qualitativo. A análise de conteúdo foi mencionada em doze dos trinta e três trabalhos.

\section{CONCLUSÕES}

A pesquisa qualitativa conquistou nos últimos anos no Brasil um espaço que permite ampliar o uso de seus instrumentos. O uso de um software para a produção de uma Análise Textual concede a pesquisa uma maior objetividade, pois, alia agilidade e clareza a todas as etapas do processo.

O software Sphinx ainda proporciona a exploração e uso de gráficos, possibilitando processos quali-quanti de pesquisa. Porém observa-se que o fato de serem utilizadas porcentagens gráficos e etc. não é suficiente para caracterizar uma análise quantitativa, para que isso ocorra deve-se atender a todos os pressupostos de pesquisa desta magnitude. No trabalho citado, evidenciou-se o uso quali, pois foram utilizados os momentos do ambiente que registraram os resultados textuais dos questionários, atendendo aos pressupostos teóricos de uma pesquisa qualitativa, conforme Bogdan \& Biklen(1991).

Considerando-se que é possível, solicitar na plataforma Sphinx que sejam realizadas correlações entre respostas oferecidas pelos sujeitos de pesquisa fica evidente que este software auxilia junto a ATD (Análise Textual Discursiva) a obtenção das Categorias Iniciais. Deste modo, este software pode ser considerado uma ferramenta útil para uma Análise Textual Discursiva, pois agiliza o processo de tabulação das informações. 
Percebe-se que há ainda necessidade de uma maior apropriação por parte de jovens pesquisadores em seus cursos de pós-graduação, em nível de stricto sensu, do uso destes softwares em análises textuais. Deste modo, o uso de editores de textos pode vir a ser um dos momentos da ATD, ao invés de constituir-se como um caminho único.

No entanto, softwares que utilizam codificações, requerem um maior cuidado por parte do jovem pesquisador, pois é preciso estar atento às ideias que estão sendo relacionadas. Isto evidencia que antes da escolha do software, o pesquisador tenha consciência e clareza do método de pesquisa que irá utilizar. A técnica em si não deve ser determinante, mas sim determinada pelos aspectos qualitativos que norteiam o tema estudado. O problema de pesquisa poderá ser revisto em função dos elementos adquiridos ao longo do percurso, mas não remodelado em função da coleta realizada com uso ou não de software para sua análise final. Deste modo, o que se pretende afirmar é que o software é um auxiliar para o pesquisador devendo ser assim percebido para que possa vir a ocupar apenas este lugar na pesquisa.

Isto se deve ao fato de que, o uso do software economiza muitas redigitações que envolvem as releituras das respostas. Pois, a digitação inicial das respostas dos sujeitos pesquisados, já exige que o pesquisador, tenha realizado, dentro dos próprios questionários respondidos, a desconstrução das respostas, realizando as partições e obtendo as unidades de sentido/significado ali apresentadas, no interior das respostas.

Deste modo, conclui-se que para o pesquisador, num estudo qualitativo, as imersões requeridas na ATD de Moraes e Galiazzi (2011), não são prejudicadas pelo uso do software Sphinx, mas sim, realizadas com uma disponibilidade maior de tempo. Resta desmistificarem-se as ideias de que para a ATD ser bem realizada é preciso o exaustivo trabalho braçal de digitações e redigitações. O que se faz necessário são diversas imersões no texto, para que as unidades de significado/sentido, possam ser adequadamente obtidas. 
Após esta fase, as junções realizadas, dependerão das escolhas do pesquisador, conforme o objetivo de sua pesquisa e não de sua opção entre um editor ou um software, pois ferramenta e metodologia ocupam lugares distintos, dentro de uma pesquisa.

\section{AGRADECIMENTOS}

À Coordenação de Aperfeiçoamento de Pessoal de Nível Superior (Capes), pelo apoio nestes dois anos de doutorado.

Ao 4 Congresso Ibero-Americano em Investigação Qualitativa (CIAIQ) e ao 6o Simpósio Internacional de Educação e Comunicação (SIMEDUC) pela seleção deste artigo, para publicação.

\section{REFERÊNCIAS}

ANDRADE, Juliana Maria Arruda de. Um estudo sobre melhoria de processos de suporte de TI no centro de informática da UFPE. Dissertação. Mestrado Profissional em Ciências da Computação. UFPE, 2011.

AZEVEDO, Breno Fabricio Terra. Minerafórum: Um recurso de apoio para análise qualitativa em fóruns de discussão. Tese. Doutorado em Informática na Educação. UFRGS, 2011.

BERTONCINI, Judite Hennemann. Entre o prescrito e o real: renormalizações possíveis no trabalho da enfermeira na saúde da família. Tese. Doutorado em Enfermagem. UFSC, 2011.

BOGDAN, Robert, BIKLEN, Sari. Investigação qualitativa em educação. Porto (PT): Porto Editora, 1991.

BORBA Marcelo de Carvalho; PENTEADO Miriam Godoy. Informática e Educação matemática. Belo Horizonte (MG): Autêntica, 2005.

CASSIARI, Edna Ribeiro. Potencialidades e fragilidades na implementação do "Caderno do Professor" e "Caderno do Aluno" da Rede Estadual de São Paulo". Dissertação. Mestrado Profissional em Educação Matemática. PUCSP, 2011.

CRUZ, Gisele Borsotte. Crack usuários identificam razões para cessar o consumo e as 
estratégias utilizadas. Dissertação Mestrado Acadêmico em Psicobiologia. UFSP, 2011.

DALBOSCO, Carla. Representações sociais de educadores de escolas públicas sobre situações-problema relacionadas ao uso de álcool e outras drogas. Tese. Doutorado em Psicologia Clínica e Cultura. UnB, 2011.

FASCIANI, Luciana Azevedo. Significado da soropositividade para crianças e adolescentes com HIV/AIDS. Dissertação. Mestrado Acadêmico em Doenças Infecciosas e Parasitárias. FUFMS, 2011.

FONSECA, Emanuel Nildivan Rodrigues da. Vivências de profissionais de saúde no processo de cuidar de mulheres soropositivas no ciclo gravídico puerperal. Dissertação. Mestrado Acadêmico em Enfermagem. UFPB, 2011.

FREITAS, H. M. R.; JANISSEK-MUNIZ, R. Guia Prático Sphinx. Canoas RS: 2009. v.1. Disponível em: <http://www.sphinxbrasil.com/produtos/softwares/versao-demonstracao>. Acesso em: mar. 2015.

GAKIYA, Simone Maria Carlos. Formação continuada e inclusão escolar de alunos com deficiência: concepções, sentimentos e práticas de educadores da rede municipal de ensino de Presidente Prudente-SP. Dissertação. Mestrado Acadêmico em Educação. UNESP, 2012.

GERONASSO, Jociane Emidia Silva. Representações sociais de professores da escola básica sobre o bullying no espaço escolar. Dissertação. Mestrado Acadêmico em Educação. PUCPR, 2012.

GERVASIO, Stela Marcia Draib. Estudo e conhecimento da enfermagem no processo de cuidado sistematizado: do manual ao informatizado. Dissertação. Mestrado Acadêmico em Engenharia Biomédica. Instituto de Engenharia Biomédica da Unicastelo, 2012.

GOES, Ubaldo Tonar Teixeira. Mapeamento cognitivo da aprendizagem telecolaborativa de professores de ciências e matemática em formação: análise de narrativas tecidas em fóruns de discussão. Dissertação. Mestrado Profissional em Ensino de Ciências e Matemática UFCE, 2012.

LAGE, Maria Campos; GODOY, Arilda, Schmidt. Uso do computador na análise de dados qualitativos: questões emergentes. RAM - Revista de Administração Mackenzie. v. 9, n. 4, edição especial, 2008, p. 75-98.

LÉVY, Pierre. As tecnologias da inteligência: o futuro do pensamento na era da informática. 2a. ed. Trad. C.I da Costa. Rio de janeiro (RJ): Editora 34, 1995.

MAGIERSKI, Tatiana. Aprendizagem e contexto organizacional: um estudo de caso em uma empresa de tecnologia da informação catarinense. Dissertação. Mestrado Acadêmico em Administração. PUCPR, 2012. 
MARTINS, Dasiele Daiane Monteiro. Consumo consciente: fatores sociais e psicológicos que influenciam na compra de produtos eletroeletrônicos com o selo PROCEL de economia de energia. Dissertação. Mestrado Acadêmico em Administração. PUCPR, 2011.

MENEZES, Edson Alves de. Territórios integrados de atenção à saúde como estratégia para a implementação da política de saúde no município do Rio de Janeiro. Dissertação. Mestrado Acadêmico em Enfermagem. UFRJ, 2011.

MINAYO, Maria Cecília de Souza; GOMES, Romeu; DESLANDES, Sueli Ferreira (Orgs.). Pesquisa Social: teoria, método e criatividade. 30a ed. Petrópolis (RJ): Editora Vozes, 2011.

MORAES Roque, GALIAZZI, Maria do Carmo. Análise Textual Discursiva: Processo reconstrutivo de múltiplas faces. Ciência \& Educação, v. 12, n. 1, 2006, p. 117-28.

Análise Textual Discursiva. 2. ed. ljuí (RS): Unijuí, 2011.

MOREIRA Daniel. Augusto. Revista de Negócios, Blumenau, v. 12, n. 2, p. 56-68, abril/junho 2007.

NASCIMENTO, Carina Diniz. Cognições de professores de inglês sobre ensino-aprendizagem: um estudo Q. Dissertação. Mestrado Acadêmico em Estudos Linguísticos. UFUBE, 2012.

NETO, Arlindo Leal Boica. Usando visualização para possibilitar a análise simultânea de documentos na aplicação da técnica coding. Dissertação. Mestrado Acadêmico em Ciência da Computação.UFSCAR, 2012.

OLIVEIRA, Annelissa Andrade Virginio de. Diagnóstico da tuberculose em pessoas idosas: barreiras de acesso. Dissertação. Mestrado Acadêmico em Enfermagem. UFPB, 2011.

ORFAO, Ronaldo Barros. Professores de matemática em um grupo de estudos: uma investigação sobre o uso de tecnologia no ensino de funções trigonométricas. Dissertação. Mestrado Acadêmico em Educação Matemática. UNIBAN, 2012.

PAULA, Marlúbia Corrêa de. Um novo olhar sobre a transposição didática: o início de uma proposta. Porto Alegre, 2014. Dissertação. Faculdade de Educação, Programa de PósGraduação em Educação em Ciências e Matemática. PUCRS. 2014.

GUIMARÃES, G., VIALI. L. Pesquisa qualitativa com o uso de softwares: ampliando as possibilidades metodológicas. No prelo 2015.

PEREIRA, Veridiana Rotondaro. Sistema Produto-Serviço - PSS: um estudo do relacionamento entre os fatores motivadores e a estruturação das empresas na integração produto-serviço. Tese. Doutorado em Engenharia (Engenharia de Produção). USP, 2012.

POCRIFKA, Dagmar Heil. Inclusão digital nas políticas públicas para formação de professores em Pernambuco. Dissertação. Mestrado Acadêmico em Educação Matemática e Tecnológica. UFPE, 2012. 
RIBEIRO, Luana Cassia Miranda. Exposição ao material biológico: as percepções das vítimas sobre seu atendimento e acompanhamento. Dissertação. Mestrado Acadêmico em Enfermagem. UFGO, 2012.

RIBEIRO, Renata Aquino. Caminhos para práticas pedagógicas inovadoras de ensino e aprendizagem: uma análise a partir dos I e II Seminários Web currículo. Tese. Doutorado em Educação (currículo). PUCSP, 2012.

ROSA, Roberta da Rocha. Estratégias de responsabilidade social corporativa: a disseminação de iniciativas com o uso da franquia social no Brasil. Dissertação. Mestrado Acadêmico em Administração. PUCPR, 2012.

ROSCOE, Maria Teresa de Azeredo. Mecanismos de intervenção adotados por famílias proprietárias de empresas familiares: estudos de caso. Dissertação. Mestrado profissional em administração instituição de ensino: pontifícia universidade católica de minas gerais. PUC MINAS, 2011.

SILVA, Gislene Pereira da. Faço parte dessa tribo: uma análise da coesão social como fator de mútuas influências virtuais no anticonsumo. Dissertação. Mestrado Acadêmico em Administração. UFPB, 2012. $232 \mathrm{f}$.

SOUZA, Ana Rosa Lins de. Contextos e padrões do uso indevido benzodiazepínicos entre mulheres: um estudo qualitativo. Dissertação. Mestrado Acadêmico em Psicobiologia UPPB, 2011.

SPINK, Mari Jane (org.). Práticas discursivas e produção no cotidiano: aproximações teóricas e metodológicas. 2ed. São Paulo (SP): Cortez (2000)

VIDAL, Ana Paula Cenci. Legislação brasileira de sementes: aplicação e eficácia na garantia da qualidade de sementes de soja. Dissertação. Mestrado Acadêmico em Agronegócios. UnB, 2012.

ZANUNCIO, Sharinna Venturim. Saúde e segurança no trabalho e vida cotidiana: a tecnologia multimídia ergoshow como prática na educação infanto juvenil em ergonomia. Dissertação. Mestrado Acadêmico em Economia Doméstica. UFViçosa, 2012.

WARMLING, Alessandra Martins Ferreira. Tecnologias de Informação e Comunicação em odontologia: desenvolvimento de um aplicativo auxiliar no ensino. Dissertação. Mestrado Acadêmico em Odontologia. UFSC, 2012. 156f.

WINDMOLLER, Arno. Favorabilidade na adoção de práticas de metodologias ágeis no desenvolvimento de software. Dissertação. Mestrado Profissional em Gestão do Conhecimento e da Tecnologia da Informação. PUCB, 2012. 